\title{
Spatial Genetic Structure of Coffee-Associated Xylella fastidiosa Populations Indicates that Cross Infection Does Not Occur with Sympatric Citrus Orchards
}

\author{
Carolina S. Francisco, Paulo C. Ceresini, Rodrigo P. P. Almeida, and Helvécio D. Coletta-Filho
}

First author: Universidade Estadual Paulista (UNESP), Campus de Jaboticabal, Graduate Program in Genetics and Plant Breeding, São Paulo, Brazil; first and fourth authors: Centro APTA Citros Sylvio Moreira, Cordeiropolis, São Paulo, Brazil; second author: UNESP, Campus de Ilha Solteira, São Paulo, Brazil; third author: Department of Environmental Science, Policy and Management, University of California, Berkeley. Current address of C. S. Francisco: Plant Pathology, Institute of Integrative Biology, ETH Zürich, CH-8092 Zürich, Switzerland. Accepted for publication 8 December 2016.

\begin{abstract}
Xylella fastidiosa, an economically important plant-pathogenic bacterium, infects both coffee and citrus trees in Brazil. Although X. fastidiosa in citrus is well studied, knowledge about the population structure of this bacterium infecting coffee remains unknown. Here, we studied the population structure of $X$. fastidiosa infecting coffee trees in São Paulo State, Brazil, in four regions where citrus is also widely cultivated. Genotyping of over 500 isolates from coffee plants using 14 genomic microsatellite markers indicated that populations were largely geographically isolated, as previously found with populations of $X$. fastidiosa infecting citrus. These results were supported by a clustering analysis, which indicated three major genetic groups among the four sampled regions. Overall, approximately $38 \%$ of isolates showed significant membership coefficients not related to their original geographical

populations (i.e., migrants), characterizing a significant degree of genotype flow among populations. To determine whether admixture occurred between isolates infecting citrus and coffee plants, one site with citrus and coffee orchards adjacent to each other was selected; over 100 isolates were typed from each host plant. No signal of natural admixture between citrus- and coffee-infecting isolates was found; artificial cross-infection assays with representative isolates also yielded no successful cross infection. A comparison determined that $X$. fastidiosa populations from coffee have higher genetic diversity and allelic richness compared with citrus. The results showed that coffee and citrus $X$. fastidiosa populations are effectively isolated from each other and, although coffee populations are spatially structured, migration has an important role in shaping diversity.
\end{abstract}

The economically important plant-pathogenic bacterium Xylella fastidiosa colonizes multiple hosts and requires insect vectors for dissemination. Although until recently reported only in the Americas, there have been recent reports from Italy and France (Almeida 2016) and Iran (Amanifar et al. 2014). Tentatively subdivided in five subspecies, this pathogen causes disease in a variety of crops such as citrus, grapevine, almond, and coffee; trees such as elm, oak, mulberry, and sycamore; as well as ornamental species including oleander (Almeida and Nunney 2015). X. fastidiosa subsp. pauca, which was thought to be limited in distribution to South America, has more recently been reported in Central America as well as Europe (Almeida and Nunney 2015). In Brazil, there are three main crops affected by $X$. fastidiosa: citrus, coffee, and plum. Most plum production is located in southern Brazil, while citrus and coffee occur sympatrically in the southeast region, primarily in São Paulo State. In citrus (Citrus sinensis L. Osbeck, sweet orange), X. fastidiosa subsp. pauca causes citrus variegated chlorosis (CVC), a wellcharacterized disease with plants exhibiting reduced growth, leaves with small lesions and yellowing, and small fruit that are not suitable for processing (de Souza et al. 2009). In contrast to the wellcharacterized CVC disease, in coffee, $X$. fastidiosa infection (coffee leaf scorch [CLS]) leads to symptoms such as leaf scorching, shortening of internodes, leaf abscission with only the most distal narrow leaves retained, and coffee fruit size reduction (de Lima et al.

Corresponding author: H. D. Coletta-Filho;

E-mail address: helvecio@centrodecitricultura.br

*The $\boldsymbol{e}$-Xtra logo stands for "electronic extra" and indicates that four supplementary figures and four supplementary tables are published online.

(C) 2017 The American Phytopathological Society
1998). Isolates of X. fastidiosa subsp. pauca infecting citrus and coffee are phylogenetically and phenotypically distinct (Almeida et al. 2008).

Brazilian coffee plantations host X. fastidiosa insect vector populations that may have high infection rates (Silva et al. 2007), which likely contribute to elevated disease prevalence and widespread distribution of this pathogen over large spatial scales (de Lima et al. 1998). Both coffee and citrus $X$. fastidiosa-infecting strains share the same xylem sap-feeding leafhopper vector species that are similar in respect to their ability to transmit $X$. fastidiosa (Marucci et al. 2008). Under laboratory conditions, one vector species was shown to be more efficient in transmitting $X$. fastidiosa to citrus compared with coffee, whereas three other species transmitted the bacterium with similar efficiency to both hosts (Marucci et al. 2008). Although vector natural infectivity in citrus orchards has not been estimated, disease prevalence can reach $100 \%$ (Coletta-Filho et al. 2013). Thus, it is plausible that the epidemiology of the diseases caused by $X$. fastidiosa subsp. pauca in citrus and coffee is similar, despite the fact that strains isolated from these host plants are distinct (Almeida et al. 2008; Nunney et al. 2012).

Brazilian populations of the citrus-infecting $X$. fastidiosa have strong spatial structure and limited genetic flow among geographical regions (Coletta-Filho and Machado 2003; Coletta-Filho et al. 2014). In contrast, no information is currently available about the genetic structure of the coffee-infecting $X$. fastidios $a$ populations. Our main objective was to study the population genetic structure of hundreds of $X$. fastidiosa coffee-infecting strains isolated from four different orchards in São Paulo, Brazil. In addition, due to high rates of migration observed, a study was performed to evaluate the occurrence of admixture between adjacent coffee and citrus $X$. fastidiosa-infected trees using orchards from the central region of São Paulo State. Finally, cross-inoculation experiments 
were done to test whether the genetic separation between coffee and citrus populations was biologically significant.

\section{MATERIALS AND METHODS}

Population sampling and DNA extraction. In total, 519 isolates of $X$. fastidiosa were obtained from coffee trees (Coffea arabica 'Mundo Novo') from four geographic regions in São Paulo State, Brazil. Another 117 isolates were obtained from a citrus (Citrus sinensis 'Pera') orchard adjacent to coffee trees in the central region of São Paulo State (Tabatinga) (Supplementary Fig. S1; Supplementary Table S4). All X. fastidiosa populations were established throughout the year 2012 by sampling $X$. fastidiosa-symptomatic tissues from coffee and citrus trees according to symptoms as described by de Lima et al. (1998) and de Souza et al. (2009), respectively. Bacteria were isolated from both symptomatic branches (3 $\mathrm{mm}$ in diameter) or leaf petioles on solid buffered charcoal yeast extract (BCYE) agar medium (Wells et al. 1981), as previously described (Almeida et al. 2001; Coletta-Filho and Machado 2003). Solid media plates were incubated at $28^{\circ} \mathrm{C}$ for at least 15 days before appearance of colonies, which were identified as $X$. fastidiosa based on fastidious growth, coloring, and polymerase chain reaction (PCR) assays using primers specific to $X$. fastidiosa subsp. pauca (Pooler and Hartung 1995), followed by triple cloning on periwinkle wilt gelrite (PWG) medium (Almeida et al. 2004). A fraction of the purified strains was stored at $-80^{\circ} \mathrm{C}$ in PW broth (Davis et al. 1981) with $40 \%$ glycerol for long-term storage. The other fraction was grown in PWG medium for an additional 5 days prior to DNA extraction and genotyping. A commercial kit was used for DNA extraction (Wizard Genomic DNA Purification Kit; Promega Corp., Madison, WI) according to the manufacturer's instruction.

Genotyping and fragment analysis. Seven variable number of tandem repeat (VNTR) loci previously described by Lin et al. (2005) and seven new ones developed for this study were used for genotyping strains (Supplementary Tables S1 and S2). Five new repeat regions on the genome of $X$. fastidiosa strain 3124 (based on the draft genome of a strain isolated from coffee plants) (unpublished data) and two from citrus reference strain 9a5c were identified with Tandem Repeat Finder, version 2.02 (Benson 1999). Primers flanking these novel repeat regions were designed with Primer3, version 0.4.0 (Untergasser et al. 2012). Multiplexed primers were used in reactions for multilocus VNTR analysis. The multiplex amplifications were performed in a final volume of $13.5 \mu$ l containing 25 to $50 \mathrm{ng}$ of DNA, $6.5 \mu \mathrm{l}$ of DreamTaq PCR Master Mix (Thermo Fisher Scientific, Waltham, MA), and variable primer pair concentrations (with a fluorescent-labeled forward primer). The following program was used for PCR amplification: a denaturation step at $95^{\circ} \mathrm{C}$ for $5 \mathrm{~min}$; followed by 35 cycles at $94^{\circ} \mathrm{C}$ for $30 \mathrm{~s}, 58^{\circ} \mathrm{C}$ for $30 \mathrm{~s}$, and $72^{\circ} \mathrm{C}$ for $45 \mathrm{~s}$; and a final of extension at $72^{\circ} \mathrm{C}$ for $10 \mathrm{~min}$. Before fragment analysis, reactions were diluted $20 \times($ set 1$)$ or $40 \times$ (sets 2, 3, 4, and 5) in sterile milli-Q water. For fragment analysis, $0.7 \mu \mathrm{l}$ of the dilution was added to $10 \mu \mathrm{l}$ of Hi-Di Formamide and $0.1 \mu \mathrm{l}$ of GeneScan 500-LIZ Size Standard (both from Life Technology, Foster City, CA). The capillary electrophoresis was ran in an ABI 3730 DNA sequencer (Life Technology) and peak size estimated in base pairs by the Peak Scanner software (version 1.0; Life Technology).

VNTR profile. The distribution of allele frequencies, the range of repeat size, and number of alleles per locus for all VNTR loci are reported in supplementary materials (Supplementary Fig. S2). Allele size was converted into number of repeat units for better visualization of VNTR evolutionary dynamics within each population. Considering the observed repeat unit increments of singlerepeat changes (the insertion or deletion of one repeat motif), we assumed a stepwise mutation model (SMM) for all analysis; similar observations were made for $X$. fastidiosa infecting grapevine (Coletta-Filho et al. 2011) and citrus (Coletta-Filho et al. 2014). Parameters such as allele size, average of number of repeats, and identification of private alleles were determined using CONVERT software, version 1.3.1 (Glaubitz 2004).

Clonal diversity. Strains with the same multilocus microsatellite genotype (MLMG) were considered as a clone or haplotype, as determined by GENODIVE, version 2.0b23 (Meirmans and van Tienderen 2004), and only one representative of each haplotype was selected per population to construct clone-corrected data sets that were used for downstream analysis. Indicators of genotypic diversity estimated included (i) number of genotypes per population; (ii) clonal fraction, calculated as $1-$ (number of different genotypes within the population)/(total number of isolates within the population) (Zhan et al. 2003); (iii) the Simpson's diversity index $(S i)$, which was estimated as $S i=1-\sum P_{r}^{2}(r=1$ to $s)$, where $P_{r}$ is the relative abundance of the $r$ th genotype at the population ( 1 represents infinite diversity and 0 no diversity) (He and $\mathrm{Hu} 2005$ ); and (iv) the genotypic distribution over populations (evenness) (Stoddart and Taylor 1988).

Genetic diversity. The level of genetic variation in populations was estimated by both genetic diversity $\left(\mathrm{H}_{\mathrm{Nei}}\right)$, corrected by the number of individual $(n)$ in a population through of the formula $\mathrm{H}_{\mathrm{Nei}}=$ $\left[\left(1-\Sigma p_{1}^{2}\right) \times(n / n-1)\right]$, where $p i$ is the frequency of allele $i$ at the locus $p$ (Nei 1978), and by the allelic richness within each geographical population. Both parameters were estimated using the software FSTAT, version 2.9.3.2 (Goudet 1995). Statistics for the significance between pairs of comparison were obtained by 1,000 randomizations. An analysis was also run to estimate genetic indices $\left(\mathrm{H}_{\mathrm{Nei}}\right.$ and allelic richness) using available data from $X$. fastidiosa populations from citrus (Coletta-Filho et al. 2014). The goal was to compare these genetic indices between coffee and citrus groups of strains to infer population size.

Linkage disequilibrium analysis. The null hypothesis that all loci are in equilibrium among populations was tested using the multilocus index of association test $\left(\mathrm{I}_{\mathrm{A}}\right)$ (Smith et al. 1993), as well as rbarD, which is less sensitive to the number of loci (Agapow and Burt 2001), with MULTILOCUS, version 1.3 (http://www.bio.ic. ac.uk/evolve/software/multilocus/). $\mathrm{I}_{\mathrm{A}}$ or rbarD values significantly different from zero indicate disequilibrium, which was tested with 1,000 randomizations.

Population differentiation. The null hypothesis of no genetic differentiation among sampled populations was tested by both $D_{\text {est }}$ (Jost 2008), using the DEMEtics package in R, and $R_{S T}$ (Slatkin 1995) using ARLEQUIN, version 3.11 (Excoffier at al. 2005). Both are analogs to the widely used population differentiation index $F_{S T}$ (Wright 1949) but more adapted to highly polymorphic markers such as microsatellites. Populations were considered significantly differentiated when the observed values of $D_{e s t}$ and $R_{S T}$ were larger than $95 \%$ of the values obtained with 1,000 bootstrapping of MLMG over the populations. Analysis of molecular variance (AMOVA) (implemented in ARLEQUIN) was performed to assess and quantify the differentiation among subpopulations (geographical regions). Analyzes of the sum of squared size differences $\left(\Phi_{\text {STAT }}\right)$ between two haplotypes were used as a distance measure (Slatkin 1995), with the significance $(P \leq 0.05)$ tested by 1,023 permutation tests. GENODIVE (version 2.0b23) was used to perform the Mantel's test to estimate correlation between matrices of geographic distances (linear kilometers drawn from the latitude and longitude of populations) and genetic distances, the latter using values of both $D_{\text {est }}$ and $\mathrm{R}_{\mathrm{ST}}$ indexes. The null hypothesis of no linear relationship between geographic and genetic distances among all pairwise populations was tested by Markov Chain Monte Carlo (MCMC) by 1,000 randomizations, assuming $P \leq 0.05$.

The number of genetic clusters was estimated with STRUCTURE, version 2.3 (Pritchard et al. 2000), using the admixture model and assuming an unknown number of populations. The analysis was run three times using 10 replications of number of populations $(K)$ ranging from 2 to 15 . For these runs, the following conditions were adopted: burn-in period at 30,000 following 300,000 replicates of the MCMC. The $K$ value with the highest likelihood was determined 
according to Evanno et al. (2005). We also performed a principal coordinate analysis with GeneAlex, version 6.5 (Peakall and Smouse 2012), to plot major patterns within a multivariate data set (e.g., multiple loci and multiple samples). This method was used to identify population structure of individuals from citrus bordered with coffee populations in the central region of São Paulo State. We note that the data set had linkage disequilibrium, violating the STRUCTURE assumption of linkage equilibrium.

Demographic parameters and historical migration. The effective population sizes and migration rates among coffee-infecting $X$. fastidios $a$ populations were inferred using a Bayesian estimation based on the MCMC method implemented in MIGRATE, version 3.0.3 (Beerli and Felsentein 2001) (Department of Biological Science, Florida State University, Tallahassee). This method allows estimation of the effective population size of populations $(\theta)$ (which, for haploids, is equal to $2 \mathrm{~N}_{\mathrm{e}} \mu$, where $\mathrm{Ne}=$ effective population size and $\mu=$ mutation rate for each locus) and migration rates between population pairs $\left(M=2 \mathrm{~N}_{\mathrm{e}} \mathrm{m}\right.$, the number of migrants exchanged per generation). The data type chosen was microsatellite data with Brownian motion assuming the SMM, with 10 distinct runs realized. A single run consisted of one long Markov chain and a static heating scheme with four temperatures (1.0, 1.3, 2.6, and 3.9). The Markov chain was carried out with 5,000 samples, sampling interval of 100 (500,000 steps), burn-in period of 10,000, and 5,000 trees recorded. Prior distribution for parameter for $\theta$ and $2 \mathrm{Nm}$ was uniform, with minimum $=0.0$, mean $=10.0$, and maximum $=20.0$. The Bayesian estimates at $95 \%$ for every parameter mode were determined considering the 0.025 and the 0.975 percentiles of their a posteriori distribution.

Natural and artificial events of cross infection by $X$. fastidiosa strains. The occurrence of natural cross infection between $X$. fastidiosa coffee and citrus strains was tested with a population (226 isolates) obtained from diseased citrus $(n=99)$ and coffee ( $n=127)$ trees grown at adjacent blocks in a farm at the central region (Tabatinga) of São Paulo State (Supplementary Fig. S1B). Identification of individuals in admixture between populations was done with STRUCTURE, as described above. The number of $X$. fastidiosa genetic clusters (subpopulations) within citrus and coffee hosts, as well which individuals belonged to each cluster, was estimated with BAPS v.5.2 (Corander et al. 2003), performing independent runs using the "clustering of individuals", as recommended by Waples and Gaggiotti (2006), with subpopulations number $(K)$ ranging from 1 to 40 . Once we identified the best value of $K$, we reanalyzed the data with BAPS using the "fixed-K module", which was run 1,000 times to identify the individuals that compose each genetic cluster. This value represents the number of times that each individual was analyzed using simulations of different allele frequencies. Based on clustering of individuals results, one randomly selected isolate of several genetic clusters was selected to conduct the artificial inoculation assays.

Mechanical infections of coffee and citrus were done to test whether strains were able to maintain successful infections over time in homologous and heterologous host combinations. All the strains used for inoculation in coffee and citrus were also inoculated in Nicotiana tabacum as a control for cell viability during inoculation and persistence of infection over time, because tobacco is highly susceptible to $X$. fastidiosa (Lopes et al. 2000). Seedlings of all tested hosts-C. sinensis Pera, Coffea arabica (L.) Mundo Novo, and Nicotiana tabacum 'Havana' - were inoculated in two different points of the main stem with $10 \mu \mathrm{l}$ of $X$. fastidiosa suspensions at $10^{8}$ $\mathrm{CFU} / \mathrm{ml}$, following methods previously described (Almeida et al. 2001). The plants were maintained inside an insect-free greenhouse. For each genotype (seven from coffee and four from citrus genetic groups, one strain per group), five homologous and five heterologous plants (coffee and citrus) were selected, and three tobacco seedlings were inoculated. Plants inoculated with phosphatebuffered saline buffer and with strain 9a5c (X. fastidiosa reference isolate, originally from citrus) were kept as negative and positive controls, respectively. The list of haplotypes used in this biological assay and the number of plants tested are provided in Supplementary Table S3; haplotypes were selected based in the clustering analysis described above. The presence of $X$. fastidiosa in the coffee and citrus plants as well as the $X$. fastidiosa-associated symptoms were evaluated at 120, 210, 300, 390, and 510 days after inoculation, and the tobacco plants only during the first three sampling dates. Leaves at inoculation point or closer were sampled and $250 \mathrm{mg}$ of petiole was disrupted and homogenized using the TissueLyser II (Qiagen, Venlo, Netherlands) for 2 min at $30 \mathrm{~Hz}$ (1,800 oscillations/min), following the DNA extraction by cetyltrimethylammonium bromide methodology (Murray and Thompson 1980). All DNA were checked for quality and standardized to $100 \mathrm{ng} / \mu \mathrm{l}$ before the amplifications by using the TaqMan Real-time quantitative PCR (qPCR) chemistry (Applied Biosystems, Foster, CA) adopting primers and probe specific to $X$. fastidiosa (Oliveira el al. 2002). DNA of $X$. fastidiosa strain 9a5c grown on PWG medium was added to healthy citrus and coffee tissues and used as a positive control for both DNA extraction and qPCR amplifications.

\section{RESULTS}

Gene and genotypic diversity. The number of alleles for the VNTR loci ranged from 4 to 17 (totaling 153 alleles). The average number of alleles per locus amplified by primers based on the genome of an $X$. fastidiosa strain from coffee (COSSR) was higher (14.8) than from primers based on oleander (OSSR $=9.7)$, grape $(\mathrm{GSSR}=9.0)$, or citrus $(\mathrm{CSSR}=7.7)$ strains. Private alleles $(n=63)$ were randomly distributed throughout populations analyzed. Strains from eastern São Paulo State hosted $56 \%$ of the total of private alleles, compared with the population from central São Paulo State that hosted only 5\%. From a total of 519 isolates of $X$. fastidiosa infecting coffee plants, 185 MLMG (35.6\%) were identified as genetically distinct haplotypes (Table 1$)$. The four different regions had distinct indexes of genotypic diversity (Table 1). The clonal fraction varied from 0.56 (eastern São Paulo State) to 0.72 (northwestern São Paulo State), while Simpson's genotypic diversity index was significantly lower for northwestern São Paulo State (0.86) in comparison with the other populations. The highest gene diversity indexes $\left(\mathrm{H}_{\mathrm{Nei}}\right.$ and allelic richness) were observed for the $X$. fastidiosa population from eastern São Paulo State (Table 1). The lower gene diversity indexes were observed for both northwestern and central São Paulo State populations, which were not statistically different from each other (Table 1).

TABLE 1. Genotypic and genetic diversity of Xylella fastidiosa populations infecting coffee plants from four different geographic regions of São Paulo State, Brazily $^{\mathrm{y}}$

\begin{tabular}{|c|c|c|c|c|c|c|c|}
\hline Populations & Sample size $(n)$ & Number of genotypes & Clonal fraction ${ }^{\mathrm{z}}$ & Evenness & Simpson's index & $\mathrm{H}_{\mathrm{Nei}}$ & Allelic richness \\
\hline Central & 127 & 44 & 0.65 & $0.49 \mathrm{a}$ & $0.96 \mathrm{a}$ & $0.54 \mathrm{c}$ & $5.06 \mathrm{c}$ \\
\hline Northwest & 60 & 17 & 0.72 & $0.39 \mathrm{c}$ & $0.86 \mathrm{~b}$ & $0.57 \mathrm{c}$ & $5.07 \mathrm{c}$ \\
\hline Center-West & 178 & 61 & 0.64 & $0.49 \mathrm{a}$ & $0.97 \mathrm{a}$ & $0.60 \mathrm{~b}$ & $5.52 \mathrm{~b}$ \\
\hline East & 154 & 63 & 0.56 & $0.41 \mathrm{~b}$ & $0.97 \mathrm{a}$ & $0.69 \mathrm{a}$ & $5.77 \mathrm{a}$ \\
\hline Overall & 519 & 185 & 0.64 & 0.44 & 0.94 & 0.60 & 5.35 \\
\hline
\end{tabular}

y Values of indexes followed by different letter were significantly different $(P \leq 0.05)$ based on 1,000 pairwise bootstraps

${ }^{\mathrm{z}}$ For details how this index was estimated, please see Materials and Methods. 
Linkage disequilibrium analysis. A nonrandom association between different alleles was detected for all coffee-infecting populations $(P \leq 0.01)$ (Table 2$)$. Values for the less-sensitive index rbarD were 0.08 to 0.33 , and were confirmed by $\mathrm{I}_{\mathrm{A}}$, with values of 0.91 to 4.29 . Both indexes indicate strong linkage disequilibrium among loci of coffee populations from $X$. fastidiosa. As a consequence, a significant percentage of allele pairs at significant disequilibrium were observed in all populations (15.4 to 84.6\%). The lowest values were observed for northwestern São Paulo State and the highest for the eastern São Paulo State populations (Table 2).

Genetic differentiation between populations. The null hypothesis of no genetic differentiation among coffee populations was tested using two statistical parameters $\left(D_{e s t}\right.$ and $\left.R_{S T}\right)$. Both $D_{e s t}$ and $R_{S T}$ indexes yielded similar results (Table 3). Except for the population pair from central São Paulo State and northwestern São Paulo State $\left(D_{\text {est }}=0.02 ; R_{S T}=0.01 ; P>0.05\right)$, all other population pairs were significantly distinct $\left(D_{\text {est }}=\right.$ from 0.36 to $0.63 ; R_{S T}=$ from 0.31 to $0.50 ; P \leq 0.05)$. AMOVA showed that $56 \%$ of the variance was attributed to within-population and $44 \%$ to among-population variability, reflecting a high value of genetic differentiation at the population level $\left(\Phi_{\mathrm{STAT}}=0.44, P \leq 0.01\right)$. Similarly to others studies with X. fastidiosa in citrus (Coletta-Filho and Machado 2003; Coletta-Filho et al. 2014), and grapevine (Coletta-Filho et al. 2011), no correlation was found between genetic differentiation index $\left(D_{\text {est }}\right.$ and $\mathrm{R}_{S T}$ ) and geographical distances among populations using the Mantel test $(r=0.012, P=0.50)$. Based on a Bayesian clustering analysis used to infer the number of genetically homogeneous groups, three subpopulations $(K=3)$ were identified (Fig. 1), despite the fact that the number of geographic populations was four. This result is in agreement with the $D_{e s t}$ and $R_{S T}$ values that indicated no subdivision between the central and northwestern São Paulo State populations of $X$. fastidiosa, also inferring three subpopulations in the data set. In fact, all genotypes from these two populations were clustered in $K-1$, together with some genotypes from center-west (37.7\%) and eastern São Paulo State (46\%) populations. The cluster $K-2$ was unique for the eastern São Paulo State genotypes while the $K$-3 cluster grouped genotypes from the center-west São Paulo State population (62.3\%) (Fig. 1).

Migration. The population size estimates of coffee-infecting $X$. fastidiosa $(\Theta=0.18$ to 0.55$)$ were not significantly different. However, the migration rates between pairs of geographical populations were asymmetrical. For example, while the central São Paulo State population contributed with a high number of migrants to the eastern São Paulo State population $\left(2 \mathrm{~N}_{\mathrm{e}} \mathrm{m}_{\mathrm{Ce} \rightarrow \mathrm{Ea}}=\right.$ 13.0 migrants/generation; $95 \%$ interval $=12.3$ to 14.7 ), the opposite migration (eastern São Paulo State population to central São Paulo State population) was six times lower $\left(2 \mathrm{~N}_{\mathrm{e}} \mathrm{m}_{\mathrm{Ea} \rightarrow \mathrm{Ce}}=2.2\right.$ migrants/ generation; $95 \%$ interval $=1.2$ to 3.5 ). Despite an asymmetrical trend, we observed that central and northwestern São Paulo State populations had exchanged the highest amount of migrants among any of the populations pairs $\left(2 \mathrm{~N}_{\mathrm{e}} \mathrm{m}_{\mathrm{Ce} \rightarrow \mathrm{Nw}}=14.4\right.$ migrants/ generation; $2 \mathrm{~N}_{\mathrm{e}} \mathrm{m}_{\mathrm{Nw} \rightarrow \mathrm{Ce}}=8.3$ ), which might explain the genotype flow detected between these two populations. On average, the coffee-infecting central São Paulo State population contributed the highest number of migrants per generation $(M$ mode $=10.7$; Bayesian 95 percentile $=8.7$ to 13.4). In contrast, the northwestern São Paulo State population received the higher number of migrants $(M$ mode $=10.5$; Bayesian 95 percentile $=7.6$ to 13.4 $)$ (Fig. 2$)$.

$X$. fastidiosa from adjacent citrus and coffee orchards: admixture of strains and genetic diversity. For the population of $226 \mathrm{X}$. fastidiosa strains established from diseased coffee $(n=127)$ and citrus $(n=99)$ trees in adjacent orchards, no evidence of admixture between populations was obtained (Fig. 3A). A defined number of populations as $K=2$ (coffee and citrus) was obtained with strains associated with their respective host plant of origin (Fig. 3A). Furthermore, analyses were performed to verify the number of genetic clusters of coffee and citrus strains. In total, 14 genetic clusters were detected, whereas 10 clusters $(71.42 \%)$ were composed exclusively of $X$. fastidiosa from coffee and 4 clusters $(28.57 \%)$ only of isolates from citrus (Fig. 3B). The $D_{e s t}$ and $\mathrm{R}_{S T}$ values between $X$. fastidiosa populations infecting citrus and coffee plants $\left(\mathrm{D}_{\text {est }}\right.$ citrus $\times$ coffee $=0.56$; $\left.\mathrm{R}_{S T \text { citrus } \times \text { coffee }}=0.91 ; P \leq 0.05\right)$ showed high genetic differentiation between both populations (Supplementary Fig. S3).

Based on genotypic richness of $X$. fastidiosa from coffee (10 genetic clusters) compared with citrus (4 genetic clusters) (Fig. 3B), a broad comparison of gene diversity indexes between populations from coffee-infecting (data set obtained in this article) and citrusinfecting $X$. fastidiosa (previously published by our group, similar but not identical sampling design with 320 strains genotyped) (Coletta-Filho et al. 2014) was performed. Genotypic diversity indexes of coffee-infecting $X$. fastidiosa populations (mean $=0.60$ and 5.82 for $\mathrm{H}_{\mathrm{NEI}}$ and allelic richness, respectively) were higher than those described for citrus populations (mean $=0.43$ and 2.82 for $\mathrm{H}_{\mathrm{NEI}}$ and allelic richness, respectively). The values of the $t_{\text {(coffee versus citrus) }}$ for differences in $\mathrm{H}_{\mathrm{NEI}}(t=2.34 \pm 0.13, P=0.038)$ and allelic richness $(t=7.00 \pm 0.64, P=0.001)$ were both significant (Supplementary Fig. S4).

Host colonization assays. Overall artificial inoculation rates reached 40 and $45 \%$ for coffee and citrus plants, respectively, as estimated at 510 days after inoculation with respective homologous $X$. fastidiosa isolates. In total, $17 \%$ of citrus plants exhibited typical

TABLE 3. Measure of pairwise population differentiation based on $D_{\text {est }}$ (bellow diagonal) and $R_{S T}$ statistics (above diagonal) for coffee populations in four regions of São Paulo State, Brazil ${ }^{z}$

\begin{tabular}{lcccc}
\hline Populations & Central & Northwest & Center-West & East \\
\hline Central & $\ldots$ & $0.01^{\mathrm{NS}}$ & $0.37^{*}$ & $0.41^{*}$ \\
Northwest & $0.02^{\mathrm{NS}}$ & $\ldots$ & $0.34^{*}$ & $0.31^{*}$ \\
Center-West & $0.42^{*}$ & $0.42^{*}$ & $\ldots$ & $0.50^{*}$ \\
East & $0.42^{*}$ & $0.36^{*}$ & $0.63^{*}$ & $\ldots$ \\
\hline z NS $=$ nonsignificant and $*$ = significant $(P \leq 0.05$, after & Bonferroni
\end{tabular}

correction), based on 1,023 randomizations.

TABLE 2. Test for random association of alleles between pairwise loci in Xylella fastidiosa populations infecting coffee plants in four regions of São Paulo State, Brazil

\begin{tabular}{|c|c|c|c|c|c|}
\hline \multirow[b]{2}{*}{ Populations } & \multicolumn{5}{|c|}{ Gametic equilibrium estimates } \\
\hline & $\mathrm{I}_{\mathrm{A}}^{\mathrm{w}}$ & $\operatorname{rbarD}^{\mathrm{w}}$ & $P^{\mathrm{x}}$ & Pairs in disequilibrium $(n)^{\mathrm{y}}$ & Pairs $(\%)^{\mathrm{z}}$ \\
\hline Central & 0.9109 & 0.0793 & $<0.001$ & 24 in 66 & 36.4 \\
\hline Northwest & 2.6070 & 0.2253 & $<0.001$ & 12 in 78 & 15.4 \\
\hline Center-West & 2.6225 & 0.2188 & $<0.001$ & 52 in 66 & 78.8 \\
\hline East & 4.2992 & 0.3363 & $<0.001$ & 77 in 91 & 84.6 \\
\hline
\end{tabular}

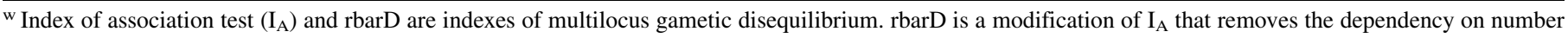
of loci.

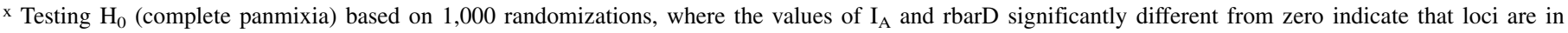
disequilibrium.

y Locus pairs in significant disequilibrium.

$\mathrm{z}$ Percent locus pairs in significant disequilibrium. 
symptoms of CVC at the end of the experiment (inoculated with CiC03 and CiC09 haplotypes) and no CLS symptoms were observed in coffee plants. On the other hand, 88 and $91.6 \%$ of $N$. tabacum plants were infected with $X$. fastidiosa strains from coffee and citrus trees, respectively. All X. fastidiosa-positive tobacco plants showed symptoms similar to those previously described (Alves et al. 2003; Lopes et al. 2000). Regarding heterologous inoculations, strains from CVC-diseased plants (CiC03, CiC05, CiC08, and CiC09) were detected in coffee plants until 300 days but did not persist any longer. CiC08 was the only isolate originally from citrus to poorly colonize that host plant species. Only one $X$. fastidiosa strain from CLS-diseased plants (CoC10) was able to persistently infect citrus plants (one of five replicates), albeit with low bacterial population estimates at 390 days after inoculation. This isolate, as well as isolate $\mathrm{CoC} 14$, also performed poorly in coffee.

\section{DISCUSSION}

The genetic diversity and population structure of coffee-infecting $X$. fastidiosa in Brazil is poorly understood. In this study, we aimed to address this knowledge gap by using a large data set of strains collected from representative coffee-growing regions of São Paulo State in Brazil. First, we tested the hypothesis that $X$. fastidiosa populations from coffee trees are geographically structured, with no admixture of isolates among regions. Most of the geographical populations were genetically isolated, albeit with the presence of historical migration. The significant isolation observed among five of the six population pairs served as an indication that the pathogen was not widely spread among the sampled regions by insect vectors or contaminated plant material. These data support the hypothesis that locally well-adapted genotypes may outcompete invaders, maintaining the spatial structure of this pathogen (Coletta-Filho et al. 2014). Alternatively, noncrop hosts can serve as local pathogen reservoirs (Lopes et al. 2003) and may influence population structure, although this hypothesis was not tested. The central and northwestern São Paulo State populations were the only population pair that was not genetically independent; it was also the pair that exchanged the highest number of migrants. We propose three hypothesis to explain this observation. First, the cause may be the acquisition of asymptomatic nursery tree material infected with $X$. fastidios $a$ from the central region and subsequent introduction onto the northwestern region for establishment of new coffee plantations. Another explanation is that these two geographical populations shared migrants from a common inoculum reservoir selective to host-specific $X$. fastidiosa genotypes, and that did not occur in other regions (Hernandez-Martinez et al. 2007; Purcell and Saunders 1999; Randall et al. 2009). Finally, it is plausible that the high levels of $X$. fastidiosa migration detected between central and northwestern São Paulo State populations may be a consequence of migrants exchanged with a third population not sampled in our study. We only studied a small number of populations, whereas coffee production in São Paulo State covers a large geographic area
A

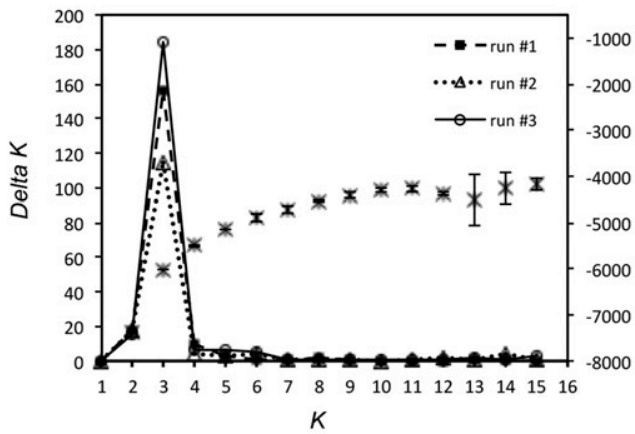

B

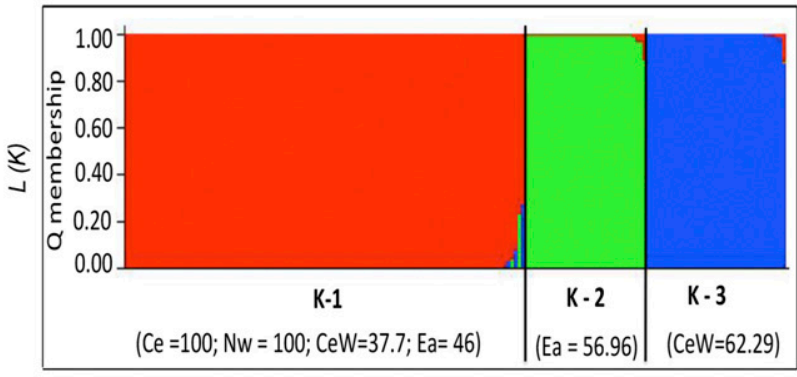

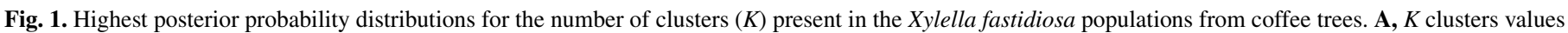

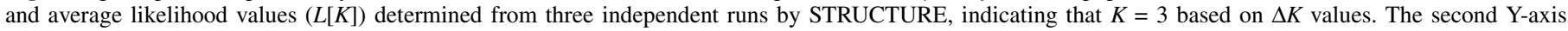

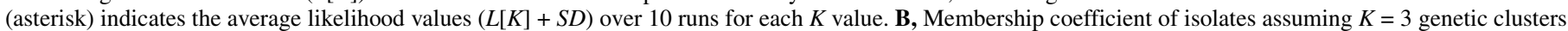

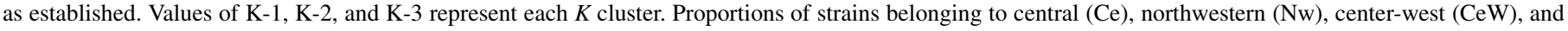
eastern $(\mathrm{Ea})$ regions of São Paulo State are shown in parentheses.



Fig. 2. Estimates of migration parameters for the coffee-infecting pathogen Xylella fastidiosa. Directions of inferred migration between source and recipient populations are indicated by shaded arrows (e.g., arrows on the left indicate inferred migration from the coffee-infecting central [Ce] Tabatinga population, while arrows on the right indicate inferred migration from the other three populations toward Ce Tabatinga). $\mathrm{Nw}=$ northwestern, CeW $=$ center-west, and Ea $=$ eastern regions. Bars indicate Bayesian estimates of inferred migration rates at $95 \%$ of the posterior distribution. 
with both large and small plantations, which we expect harbor $X$. fastidiosa genetic diversity not sampled in this study.

The structuring of populations was also observed in previous studies of citrus-infecting $X$. fastidiosa (Coletta-Filho and Machado 2003; Coletta-Filho et al. 2014). We postulate that similar patterns of genetic structure observed for both coffee- and citrus-infecting $X$. fastidiosa populations are a result of shared ecological traits. Those include vector dispersal of inoculum by the same sharpshooter leafhopper species (Marucci et al. 2008; Silva et al. 2007), which are potentially important but apparently inefficient for long-distance dispersal of the pathogen (Coletta-Filho et al. 2014). Another factor is that genetic structuring of bacterial populations can lead to linkage disequilibrium even in the presence of recombination (Feil 2010). Because $X$. fastidiosa is naturally competent (Kung and Almeida 2011) and $X$. fastidiosa subsp. pauca infecting coffee and citrus has been suggested to be of recombinogenic origin (Nunney et al. 2012), the departure from linkage equilibrium observed here may be a consequence of geographic structuring, admixture events, and limited genotype flow among the regions. In this case, linkage disequilibrium would occur due to barriers to gene exchange (e.g., geographic or ecological) or by an epidemic expansion in which case linkage disequilibrium would be temporary. Alternatively, as mentioned above, local alternative pathogen reservoirs may preferentially harbor distinct genetic variants.

In São Paulo State, farming of coffee had a boom cycle in the 1880s (Font 2010), while the intensification of citrus farming only began 80 years later, reaching a commercial large scale in the 1960 s. It is possible that endemic $X$. fastidios $a$ first adapted to coffee plants, increasing the effective population size until it adapted more recently and infected citrus (Nunney et al. 2012). CVC was first reported in 1987 (Rossetti et al. 1990) and is still under geographical expansion in a fairly restricted host range (only four Citrus sinensis cultivars which are clonally propagated, representing up to 190 million trees in São Paulo State), while the disease in coffee was first reported a decade later (de Lima et al. 1998). Symptoms of
$X$. fastidiosa in coffee plants may have been attributed to other abiotic and biotic disorders (de Lima et al. 1998). Regardless, available data now suggest that $X$. fastidios $a$ first adapted to coffee and only later to citrus plants (Nunney et al. 2012). The longer exposure of coffee plants to $X$. fastidiosa infection would lead to higher genetic and genotypic diversity in coffee than in populations that infect citrus, explaining the lower diversity indexes found in $X$. fastidiosa from citrus compared with coffee in this study. Higher diversity indexes are generally associated with older populations with equilibrium between mutation and genetic drift forces (Haag et al. 2005). In contrast, the lack of gene diversity has been associated with younger, recently founded populations (Balloux 2010; Haag et al. 2005). Nunney et al. (2012) hypothesized that strains of $X$. fastidiosa infecting citrus and coffee plants originated from a common ancestor, not yet identified. In turn, Nunes et al. (2003) presented evidence of recombination between $X$. fastidiosa subsp. pauca and subsp. multiplex in Brazilian strains, which was corroborated later with a larger number of strains obtained from coffee and citrus plants (Almeida et al. 2008; Nunney et al. 2012). Although the results presented here do not address this broader question, larger genetic diversity from coffee strains suggests that $X$. fastidiosa has been colonizing this host longer than citrus.

Despite of the similar patterns of geographic structure for X. fastidiosa causing CVC and CLS, these populations are genetically and biologically different, as previously reported (Almeida et al. 2008). Based on cross-infection assays, citrus strains were able to persistently infect coffee plants but no coffee strain was detected infecting citrus plants. Almeida et al. (2008) and Prado et al. (2008) also did not detect citrus strains infecting coffee plants over time, even after an initial infection was detected. Early colonization and detection of $X$. fastidios in host plants that is not followed by systemic and persistent infection is common for this pathogen (Purcell and Saunders 1999). Plant colonization factors required for $X$. fastidiosa multiplying and moving within hosts appears to be conserved among $X$. fastidiosa strains, and the mechanisms driving host specificity remain to be


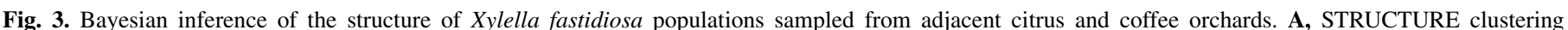

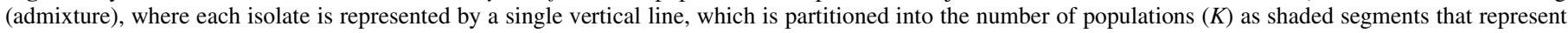

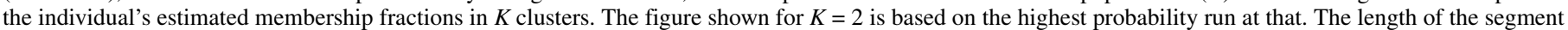



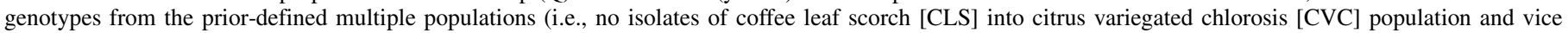

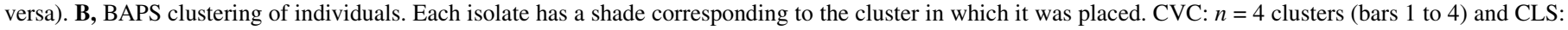
$n=10$ clusters (bars 5 to 14). The width of each bar is proportional for the number of isolates for each cluster. 
determined, although it has been suggested that the core machinery is shared among different genotypes (Killiny and Almeida 2011).

The results obtained here by using a large number of isolates support previous work showing that cross infection by citrus and coffee $X$. fastidiosa strains does not occur in natural or artificial conditions. These findings reinforced the unnecessary control of vectors in coffee trees adjacent to citrus orchards aiming to block $X$. fastidiosa cross infection. In addition, the genetic structure of $X$. fastidiosa populations causing disease in coffee trees was genetically and geographically structured, similar to that previously found for $X$. fastidiosa populations from citrus. However, coffee isolates of this pathogen showed genetic diversity and allelic richness values higher than those found in populations infecting citrus, suggesting that these represent older populations. Future work with genome sequences linked to plant-pathogenicity assays will be necessary to address pending questions about the evolution of host specificity of $X$. fastidiosa subsp. pauca in Brazil.

\section{ACKNOWLEDGMENTS}

This study was funded by a Fundação de Amparo à Pesquisa do Estado de São Paulo (FAPESP) award (project number 2011/13803-9). C. S. Franciso thanks FAPESP (São Paulo Research Foundation, project number 2011/ 14479-0) for the master's degree scholarship. H. D. Coletta-Filho and P. C. Ceresini acknowledge CNPq (Brazilian National Council for Scientific and Technological Development) for Pq-2 research fellowships (302100/2010-5 and Pq-2 307361/2012-8). We also thank the growers who granted us access to their farms.

\section{LITERATURE CITED}

Agapow, P. M., and Burt, A. 2001. Indexes of multilocus linkage disequilibrium. Mol. Ecol. Notes 1:101-102.

Almeida, R. P. P. 2016. Can Apulia's olive trees be saved? Science 353: 346-348.

Almeida, R. P. P., Mann, R., and Purcell, A. H. 2004. Xylella fastidiosa cultivation on a minimal solid defined medium. Curr. Microbiol. 48:368-372.

Almeida, R. P. P., Nascimento, F. E., Chau, J., Prado, S. S., Tsai, C. W., Lopes, S. A., and Lopes, J. R. S. 2008. Genetic structure and biology of Xylella fastidiosa causing disease in citrus and coffee in Brazil. Appl. Environ. Microbiol. 74:3690-3701.

Almeida, R. P. P., and Nunney, L. 2015. How do plant diseases caused by Xylella fastidiosa emerge? Plant Dis. 99:1457-1467.

Almeida, R. P. P., Pereira, E. F., Purcell, A. H., and Lopes, J. R. S. 2001. Multiplication and movement of a citrus strain of Xylella fastidiosa within sweet orange. Plant Dis. 85:382-386.

Alves, E., Kitajima, E. W., and Leite, B. 2003. Interaction of Xylella fastidiosa with different cultivars of Nicotiana tabacum: A comparison of colonization patterns. J. Phytopathol. 151:500-506.

Amanifar, N., Taghavi, M., Izadpanah, K., and Babaei, G. 2014. Isolation and pathogenicity of Xylella fastidiosa from grapevine and almond in Iran. Phytopathol. Mediterr. 53:318-327.

Balloux, F. 2010. Demographic influences on bacterial population structure. Pages 103-120 in: Bacterial Population Genetics in Infectious Disease, 1st ed. D. A. Robinson, D. Falush, and E. J. Feil, eds. John Wiley \& Sons, Inc., Hoboken, NJ.

Beerli, P., and Felsentein, J. 2001. Maximum likelihood estimation of a migration matrix and effective population size in $\mathrm{n}$ subpopulation by using a coalescent approach. Proc. Natl. Acad. Sci. USA 98:4563-4568.

Benson, G. 1999. Tandem repeats finder: A program to analyze DNA sequences. Nucleic Acids Res. 27:573-580.

Coletta-Filho, H. D., Bittleston, L. S., and Almeida, R. P. P. 2011. Spatial genetic structure of a vector-borne generalist pathogen. Appl. Environ. Microbiol. 77:2596-2601.

Coletta-Filho, H. D., Francisco, C. S., and Almeida, R. P. P. 2014. Temporal and spatial scaling of the genetic structure of vector-borne plant pathogen. Phytopathology 104:120-125.

Coletta-Filho, H. D., Gonçalves, F. P., Amorin, L., Machado, M. A., and de Souza, A. A. 2013. Survey of Xylella fastidiosa and citrus variegated chlorosis in Sao Paulo State, Brazil. J. Plant Pathol. 1:12-18.

Coletta-Filho, H. D., and Machado, M. A. 2003. Geographical genetic structure of Xylella fastidiosa from citrus in São Paulo State, Brazil. Phytopathology 93:28-34.

Corander, J., Waldmann, P., and Sillanpaa, M. 2003. Bayesian analysis of genetic differentiation between populations. Genetics 163:367-374.
Davis, M. J., French, W. J., and Schaad, N. W. 1981. Axenic culture of the bacteria associated with phony disease of peach and plum leaf scald. Curr. Microbiol. 6:309-314.

de Lima, J. E. O., Miranda, V. S., Hartung, J. S., Brlansky, R. H., Coutinho, A., Roberto, S. R., and Carlos, E. F. 1998. Coffee leaf scorch bacterium: Axenic culture, pathogenicity, and comparison with Xylella fastidiosa of citrus. Plant Dis. 82:94-97.

de Souza, A. A., Takita, M. A., Amaral, A. M., Coletta-Filho, H. D., and Machado, M. A. 2009. Citrus tree and forestry science and biotechnology: Citrus responses to the Xylella fastidiosa infection, the causal agent of citrus variegated chlorosis. Glob. Sci. Books 3:73-80.

Evanno, G., Regnaut, S., and Goudet, J. 2005. Detecting the number of clusters of individuals using the software STRUCTURE: A simulation study. Mol. Ecol. 14:2611-2620

Excoffier, L., Laval, G., and Schneider, S. 2005. Arlequin (version 3.0): An integrated software package for population genetics data analysis. Evol. Bioinf. 1:47-50.

Feil, E. J. 2010. Linkage, selection, and clonal complex. Pages 19-35 in: Bacterial Population Genetics in Infectious Disease, 1st ed. D. A. Robinson, D. Falush, and E. J. Feil, eds. John Wiley \& Sons, Inc., Hoboken, NJ.

Font, M. A. 2010. Coffee and Transformation in São Paulo, Brazil. Lexington Books, Lanham, MD.

Glaubitz, J. C. 2004. CONVERT: A user friendly program to reformat diploid genotypic data for commonly used population genetic software packages. Mol. Ecol. Notes 4:309-310.

Goudet, J. 1995. FSTAT (version 1.2): A computer program to calculate F-statistics. J. Hered. 86:485-486.

Haag, C. R., Riek, M., Hottinger, J. W., Pajunen, V. I., and Ebert, D. 2005. Genetic diversity and genetic differentiation in Daphnia meta-populations with subpopulations of known age. Genetics 170:1809-1820.

He, F., and Hu, S. X. 2005. Hubbell's fundamental biodiversity parameter and the Simpson diversity index. Ecol. Lett. 8:386-390.

Hernandez-Martinez, R., de la Cerda, K. A., Costa, H. S., Cooksey, D. A., and Wong, F. P. 2007. Phylogenetic relationships of Xylella fastidiosa strains isolated from ornamentals in southern California. Phytopathology 97:857-864.

Jost, L. 2008. G ST $_{\text {Th }}$ and its relatives do not measure differentiation. Mol. Ecol. 17:4015-4026.

Killiny, N., and Almeida, R. P. P. 2011. Gene regulation mediates host specificity of a bacterial pathogen. Environ. Microbiol. Rep. 3:791-797.

Kung, S. H., and Almeida, R. P. P. 2011. Natural competence and recombination in the plant pathogen Xylella fastidiosa. Appl. Environ. Microbiol. 77:5278-5284.

Lin, H., Civerolo, E. L., Hu, R., Barros, S., Francis, M., and Walker, M. A. 2005. Multilocus simple sequence repeat markers for differentiating strains and evaluating genetic diversity of Xylella fastidiosa. Appl. Environ. Microbiol. 71:4888-4892.

Lopes, S. A., Marcussi, S., Torres, S. C. Z., Souza, V., Fagan, C., França, S. C., Fernandes, N. G., and Lopes, J. R. S. 2003. Weeds as alternative hosts of the citrus, coffee, and plum strains of Xylella fastidiosa in Brazil. Plant Dis. 87:544-549.

Lopes, S. A., Ribeiro, M., Roberto, R. G., França, S. C., and Santos, J. M. 2000. Nicotiana tabacum as an experimental host for the study of plantXylella fastidiosa interactions. Plant Dis. 84:827-830.

Marucci, R. C., Lopes, J. R. S., and Cavachioli, R. R. 2008. Transmission efficiency of Xylella fastidiosa by sharpshooters (Hemiptera: Cicadellidae) in coffee and citrus. J. Econ. Entomol. 101:1114-1121.

Meirmans, P. G., and van Tienderen, P. H. 2004. GenoType and GenoDive: Two programs for the analysis of genetic diversity of asexual organisms. Mol. Ecol. Notes 4:792-794.

Murray, M. G., and Thompson, W. F. 1980. Rapid isolation of high molecular weight plant DNA. Nucleic Acids Res. 8:4321-4326.

Nei, M. 1978. Estimation of average heterozygosity and genetic distance from a number of individuals. Genetics 89:538-590.

Nunes, L. R., Rosato, Y. B., Muto, N. H., Yanai, G. M., da Silva, V. S., Leite, D. B., Gonçalves, E. R., De Souza, A. A., Coletta-Filho, H. D., Machado, M. A., Lopes, S. A., and de Oliveira, R. C. 2003. Microarray analyses of Xylella fastidiosa provide evidence of coordinated transcription control of laterally transferred elements. Genome Res. 13:570-578.

Nunney, L., Yuan, X., Bromley, R. E., and Stouthamer, R. 2012. Detecting genetic introgression: High levels of intersubspecific recombination found in Xylella fastidiosa in Brazil. Appl. Environ. Microbiol. 78:4702-4714.

Oliveira, A. C., Vallim, M. A., Semighini, C. P., Araújo, W. L., Goldman, G. H., and Machado, M. A. 2002. Quantification of Xylella fastidiosa from citrus trees by real-time polymerase chain reaction assay. Phytopathology 92:1048-1054.

Peakall, R., and Smouse, P. E. 2012. GenAlEx 6.5: Genetic analysis in Excel. Population genetic software for teaching and research-An update. Bioinformatics 28:2537-2539.

Pooler, M. R., and Hartung, J. S. 1995. Specific PCR detection and identification of Xylella fastidiosa strains causing citrus variegated chlorosis. Curr. Microbiol. 31:377-381. 
Prado, S. S., Lopes, J. R. S., Demétrio, C. G. B., Borgatto, A. F., and Almeida, R. P. P. 2008. Host colonization differences between citrus and coffee isolates of Xylella fastidiosa in reciprocal inoculation. Sci. Agric. 65: 251-258.

Pritchard, J. K., Stephens, M., and Donnelly, P. 2000. Inference of population structure using multilocus genotype data. Genetics 155:945-959.

Purcell, A. H., and Saunders, S. R. 1999. Fate of Pierce's disease strains of Xylella fastidiosa in common riparian plants in California. Plant Dis. 83: 825-830.

Randall, J. J., Goldberg, N. P., Kemp, J. D., Radionenko, M., French, J. M., Olsen, M. W., and Hanson, S. F. 2009. Genetic analysis of a novel Xylella fastidiosa subspecies found in the southwestern Unites States. Appl. Environ. Microbiol. 75:5631-5638.

Rossetti, V., Garnier, M., Bové, J. M., Beretta, M. J. G., Teixeira, A. R. R., Quaggio, J. A., and De Negri, J. D. 1990. Présence de bactéries dans le xylème d'orangers atteints de chlorose variégé, une nouvelle maladie des agrumes au Bresil. C. R. Acad. Sci., Ser. III. 30:345-349.

Silva, M. R. L., Meneguim, A. M., Paião, F. G., Meneguim, L., Canteri, M. G., and Leite, R. P., Jr. 2007. Natural infectivity of Xylella fastidiosa Wells et al. in sharpshooters (Hemiptera: Cicadellidae) from coffee plantations of Parana, Brazil. Neotrop. Entomol. 36:274-281.
Slatkin, M. 1995. A measure of population subdivision based on microsatellite allele frequencies. Genetics 139:457-462.

Smith, M. J., Smith, N. H., O’Rourke, M., and Spratt, B. G. 1993. How clonal are bacteria? Proc. Natl. Acad. Sci. USA 90:4384-4388.

Stoddart, J. A., and Taylor, J. F. 1988. Genotype diversity: Estimation and prediction in samples. Genetics 118:705-711.

Untergasser, A., Cutcutache, I., Koressaar, T., Ye, J., Faircloth, B. C., Remm, M., and Rozen, S. G. 2012. Primer3 new capabilities and interfaces. Nucleic Acids Res. 40:e115.

Waples, R. S., and Gaggiotti, O. E. 2006. What is a population? An empirical evaluation of some genetic methods for identifying the number of gene pools and their degree of connectivity. Mol. Ecol. 15:1419-1439.

Wells, J. M., Raju, B. C., Nyland, G., and Lowe, S. W. 1981. Medium for isolation and growth of bacteria associated with plum leaf scald and phony peach diseases. Appl. Environ. Microbiol. 42:357-363.

Wright, S. 1949. The genetical structure of populations. Ann. Eugen. 15: 323-354.

Zhan, J., Pettway, R. E., and McDonald, B. A. 2003. The global genetic structure of the wheat pathogen Mycosphaerella graminicola is characterized by high nuclear diversity, low mitochondrial diversity, regular recombination, and gene flow. Fungal Genet. Biol. 38:286-297. 